\title{
Light-driven catalyst-free access to phthalazines: Merging two metal-free domino reactions in one-pot
}

\author{
Anton Guryev, ${ }^{[a]}$ Florian Schuster ${ }^{[a]}$ and Svetlana B. Tsogoeva*[a] \\ [a] Dr. A. Guryev, F. Schuster, Prof. Dr. S. B. Tsogoeva \\ Organic Chemistry Chair I and Interdisciplinary Center for Molecular Materials (ICMM) \\ Friedrich-Alexander-University Erlangen-Nürnberg \\ Nikolaus Fiebiger-Straße 10, 91058 Erlangen, Germany \\ E-mail: svetlana.tsogoeva@,fau.de
}

Keywords: light-driven domino reaction $\bullet$ photoenolization $\bullet$ Diels-Alder reaction $\bullet$ one-pot reaction $\bullet$ phthalazines

\begin{abstract}
We report the development of an unprecedented metal-free four-step one-pot synthetic strategy to access high-value functionalized phthalazines using o-methyl benzophenones as starting compounds. Combination of a light-mediated enolization of o-methyl benzophenones/Diels-Alder reaction domino process with a subsequent deprotection/aromatization domino reaction in onepot leads to sustainable and efficient organic synthesis. The tangible advantages, i.e. absence of catalysts or additives, utilization of commercially available and/or easily accessible substrates, mild reaction conditions, simplicity, and single work-up procedure, make this combined process highly appealing for the direct construction of various 1-aryl-phthalazines.
\end{abstract}

\section{Introduction}

Among diverse $N$-heterocycles, phthalazines represent a valuable class of compounds and are important subunits of a broad variety of natural products with remarkable biological activities ${ }^{1-3}$ and are ubiquitous in pharmaceuticals..$^{4-6}$ An impressive number of known drugs contain a phthalazine core, e.g., hydralazine (used to treat high blood pressure and heart failure), ${ }^{7}$ carbazeran (potent cardiac stimulant) ${ }^{8}$ and vatalanib (anti-cancer drug) $)^{9,10}$ and recently reported drug candidate A-196 (potent and selective inhibitor of protein lysine methyltransferases (PKMTs) (Figure 1a). ${ }^{11}$

Besides, phthalazine-based compounds are widely employed as catalysts $^{12}$ or ligands in a variety of transition metal complexes. ${ }^{13-16}$ Apart from that, they act as key intermediates in organic synthesis. For instance, they can undergo a thermal rearrangement reaction towards corresponding quinazolines in high yield. ${ }^{17}$

Commonly, phthalazine derivatives can be obtained by ringclosing reactions of either $o$-dicarbonyl compounds with hydrazine reagents, ${ }^{18,19}$ aromatic aldazines, ${ }^{20}$ or arylhydrazines ${ }^{21}$ maintained in liquid aluminum chloride or by refluxing in presence of zinc chloride. However, these and related methods ${ }^{22,23}$ require mostly toxic reagents and harsh reaction conditions. Therefore, development of new environmentally friendly and efficient methodologies for synthesis of substituted phthalazines is highly desirable.

Recently, domino and one-pot processes have attracted much attention, since they avoid a lengthy separation and purification process of intermediate products and, therefore, minimize chemical waste and save resources. ${ }^{24-28}$

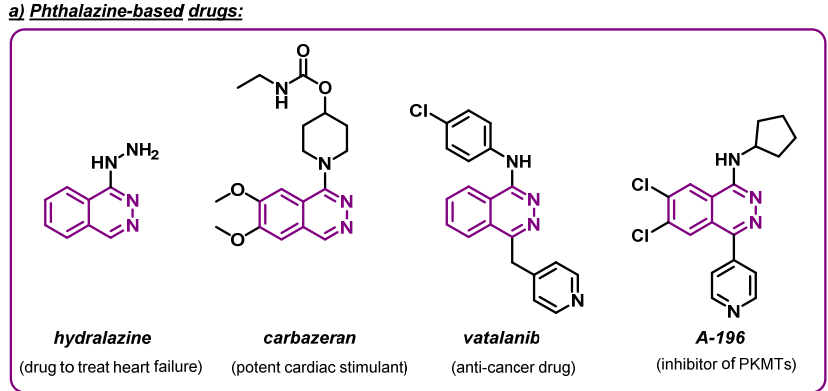

b) Previuos work (Ref. 35):

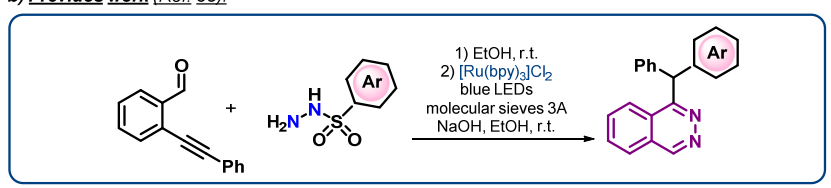

c) This work:

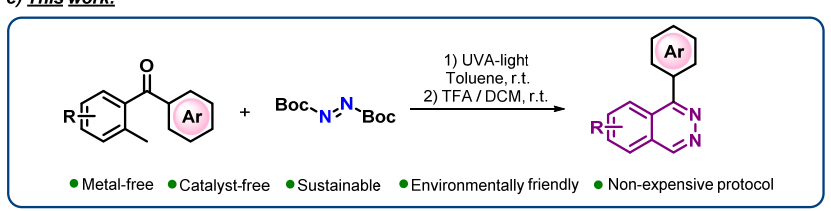

Figure 1. a) Selected examples of phthalazine-based drugs. b) Previous photochemical protocol towards phthalazines. ${ }^{35}$ c) Lightdriven metal-free protocol developed in this work.

Especially photochemical domino and one-pot transformations have a high appeal, as light is an abundant, clean, and renewable reagent in chemistry. ${ }^{29-34}$ Until the present, only a single example of photochemical synthesis of phthalazine derivatives was reported through $\left[\mathrm{Ru}(\mathrm{bpy})_{3}\right] \mathrm{Cl}_{2}$ catalyzed photoredox one-pot 
process, combining a radical hydroamination reaction followed by a Smiles rearrangement (Figure 1b). ${ }^{35}$

While ruthenium metal-based complexes are very efficient photosensitizers and/or photoredox catalysts, this metal is expensive and not abundant. Therefore, a metal-free photochemical synthetic route towards phthalazine derivatives is highly desirable but has not been reported so far. Herein, we report a first example of a metal-free one-pot process (Figure 1c) involving light-induced photoenolization of o-methyl benzophenones as a key step towards new phthalazine derivatives. Specifically, we present a combined process, which joins a metal- and catalystfree hetero-Diels-Alder reaction between long-wavelength UVgenerated $o$-quinodimethanes and di-tert-butyl azodicarboxylate with a subsequent deprotection and aromatization (Figures 2 and 3). This facile four-step one-pot sequence, with only a single work-up procedure, results in new functionalized phthalazines with yields up to $66 \%$.

\section{Results and Discussion}

The photochemical enolization ${ }^{36}$ of $o$-alkyl benzophenones towards transient substituted $o$-quinodimethanes or $o$-xylylenes is a remarkable and extensively investigated transformation. ${ }^{37}$ The mechanism of this reaction, which was discovered by Cava and Napier in $1957^{38}$ and later extended by Yang and Rivas, ${ }^{39}$ has been comprehensively studied by flash photolysis, ${ }^{40}$ ultrafast la$\mathrm{ser}^{41,42}$ and supersonic jet spectroscopies, ${ }^{43}$ paramagnetic resonance $e^{44,45}$ and time-resolved thermal lensing ${ }^{46}$ techniques, as well as by isotope exchange and trapping studies. ${ }^{47-50}$ Moreover, theoretical investigations have been carried out. ${ }^{51}$ The photochemically generated $o$-quinodimethanes have been extensively used as dienes in the Diels-Alder cycloaddition in the synthesis of substituted achiral and chiral tetralines. ${ }^{52,53}$ The group of Melchiorre made a remarkable contribution to this field, not only by developing an asymmetric method and for obtaining chiral tetralines with high level of enantiocontrol, but also by exploring other reactions of photogenerated o-quinodimethanes. $^{54,55}$

Until the present, photochemical metal-free synthesis of phthalazines via photogenerated $o$-quinodimethanes has failed. ${ }^{56}$ While a tetrahydrophthalazine derivative was observed in reaction of diethyl azodicarboxylate with photodiene of $o$-methyl benzophenone, it could, however, not be converted into a phthalazine. ${ }^{56}$ We envisaged that substitution of diethyl azodicarboxylate by di-tert-butyl azodicarboxylate as dienophiles in photochemically induced Diels-Alder reactions and subsequent hydrolysis of Boc groups could enable aromatization of tetrahydrophthalazine product intermediates towards phthalazines. We initiated our study, using commercially available o-methyl benzophenone (1a) as a model substrate (Table 1). To our delight, the test reaction in presence of di-tert-butyl azodicarboxylate ( 2 equiv.) followed by a subsequent cleavage of tert-butyloxycarbonyl (Boc) in presence of trifluoroacetic acid (TFA) lead to formation of 1-phenylphthalazine in $20 \%$ yield (Table 1, Entry 1). Increasing amount of di-tert-butyl azodicarboxylate to 4 and 5 equiv. improved the yield to $51 \%$ and $54 \%$, respectively (Table 1, Entries 2 and 4). However, increasing amount of di-tert-butyl azodicarboxylate to 6 equiv. resulted in $46 \%$ yield (Table 1, Entry 5). When the reaction was performed in more concentrated solution, it resulted in only $29 \%$ yield of desired product (Table 1, Entry 3 ). Carrying out the reaction in more diluted solution led to shorter reaction time almost without loss of yield (Table 1, Entry 6). Next, we performed the reaction in degassed toluene using freeze-pump-thaw cycling as it was previously shown, that in aerated solutions, photogenerated $o$-xylylenes can be easily trapped by dissolved oxygen forming cyclic peroxides. ${ }^{57}$ Indeed, conducting reaction in degassed toluene improved the yield to $59 \%$ (Table 1, Entry 7). Optimization of the amount of TFA necessary for removal of the Boc protecting groups and subsequent aromatization step let us further improve the yield to $66 \%$ (Table 1, Entry 8 ). It is worthwhile noting that calculated average yield of every individual step in this four-step one-pot transformation is up to $90 \%$.

In absence of light at room temperature, no product formation was observed (Table 1, Entry 9). The same results were obtained by performing the reaction at $50{ }^{\circ} \mathrm{C}$ or by refluxing for 3 hours (Table 1, Entries 10 and 11). Notably, upon prolonged refluxing, the o-methyl-benzophenone remained unchanged, while di-tert-butyl azodicarboxylate was completely decomposed (Table 1, Entry 12). Thus, the presence of light proved to be crucial for the reaction.

Table 1. Optimization of the reaction conditions.

\begin{tabular}{|c|c|c|c|c|c|}
\hline & & $\mathrm{N}_{\text {Boc }}$ & $\begin{array}{l}\text { 1) UV } \\
(320-4 \\
\text { Toluene } \\
\begin{array}{c}\text { 2) TFA } \\
\text { time }\end{array}\end{array}$ & $\underset{\mathrm{M}}{\stackrel{\mathrm{m})}{\mathrm{r.t.}}}$ & $\underbrace{P h}_{\substack{N \\
N \\
N}}$ \\
\hline Entry & $\begin{array}{l}\text { DBAD, } \\
\text { equiv }\end{array}$ & toluen &, $\mathrm{M}^{[\mathrm{a}]}$ & time, $\mathrm{h}$ & Yield, \% \\
\hline 1 & 2 & 0.1 & & 2 & 20 \\
\hline 2 & 4 & 0.1 & & 7 & 51 \\
\hline 3 & 4 & 0.2 & & 7 & 29 \\
\hline 4 & 5 & 0.1 & & 4 & 54 \\
\hline 5 & 6 & 0.1 & & 8 & 46 \\
\hline 6 & 5 & 0.05 & & 3 & 49 \\
\hline $7^{[\mathrm{b}]}$ & 5 & 0.05 & & 3 & 59 \\
\hline $8^{[\mathrm{b}, \mathrm{c}]}$ & 5 & 0.05 & & 3 & 66 \\
\hline $9^{[\mathrm{d}]}$ & 5 & 0.05 & & 3 & n.r. \\
\hline $10^{[\mathrm{e}]}$ & 5 & 0.05 & & 3 & n.r. \\
\hline $11^{[\mathrm{f}]}$ & 5 & 0.05 & & 3 & n.r. \\
\hline $12^{[\mathrm{f}]}$ & 5 & 0.05 & & 18 & n.r. \\
\hline
\end{tabular}

${ }^{[a]}$ With respect to 1a. ${ }^{[b]}$ Degassed toluene. ${ }^{[c]}$ TFA-DCM $=1: 1(4$ $\mathrm{mL}$ ). Reactions in absence of light: ${ }^{[\mathrm{d}]}$ at r.t.; ${ }^{[\mathrm{e}]}$ at $50{ }^{\circ} \mathrm{C} ;{ }^{[\mathrm{f}]}$ at reflux. DBAD $=$ di-tert-butyl azodicarboxylate; n.r. $=$ no reaction.

The scope of developed reaction was explored, using a set of $o$ methyl benzophenones 1a-18a, and the results are summarized in Figure 2. First, influence of substituent at para-position of the phenyl ring of o-methyl benzophenone was examined. Several electron-donating groups (EDG), namely methyl, methoxy and benzyloxy, were well tolerated in the developed reaction and gave the corresponding phthalazines $\mathbf{2 b}, \mathbf{3 b}$, and $\mathbf{4 b}$ with good yields of $52 \%, 58 \%$ and $55 \%$, respectively. Substrates, bearing electron-withdrawing groups (EWG) in para-, orthoand meta-positions, however, resulted in the desired 1-arylphthalazines in slightly lower yields (40-48\% for products $\mathbf{5 b}$ 9b). 


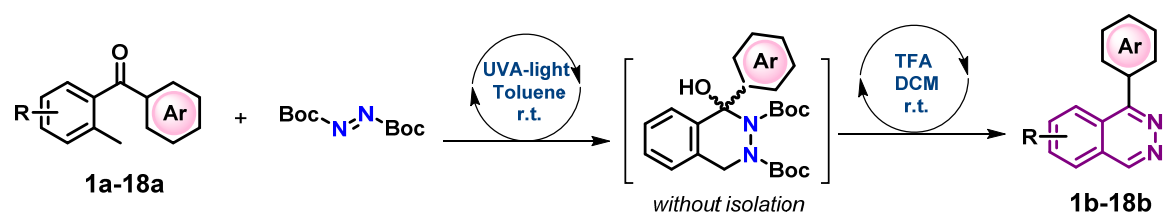<smiles></smiles><smiles></smiles>

$$
\text { 2b }
$$

$1 \mathrm{~b}$
$66 \%$ yield<smiles>c1ccc2c(-c3cnccn3)nncc2c1</smiles>

$10 \mathrm{~b}$ $10 \%$ yield<smiles>c1ccc(C2N=NCc3ccccc32)nc1</smiles>

$$
\text { 11b }
$$

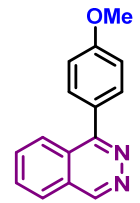

3b $58 \%$ yield<smiles>c1cncc(-c2nncc3ccccc23)c1</smiles>

12b<smiles></smiles>

4b $55 \%$ yield<smiles>c1ccc2c(-c3ccncc3)nncc2c1</smiles>

13b<smiles></smiles>

$5 b$ $46 \%$ yield

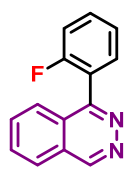

6b $42 \%$ yield<smiles></smiles>

7b $48 \%$ yield<smiles></smiles>

$8 b$ $47 \%$ yield

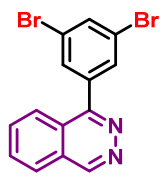

9b $40 \%$ yield

Figure 2. Substrate scope of a new one-pot four-step reaction towards 1-aryl-phthalazines.

The reaction also allows to introduce N-heterocycles at the 1position of the product (see compounds 10b-15b). Notably, yields of para- and meta-substituted pyridines $\mathbf{1 2 b}$ and $\mathbf{1 3 b}$ are higher than for ortho-substituted pyridine 11b. Electron-withdrawing substituents at the phthalazine core are also well tolerated: the products $\mathbf{1 5 b - 1 8 b}$ are obtained with notable yields of $27 \%-60 \%$. Nonetheless, presence of chlorine substituents at the benzene ring of the phthalazine core (cf. 15b vs. 13b) exhibits a significantly lower yield (of $27 \%$ and $38 \%$, respectively). Surprisingly, para-cyano-substituted product is obtained in a much higher yield when chlorine substituents are present at the phthalazine moiety (17b, $60 \%$ yield), in comparison to product $\mathbf{5 b}$ (46\% yield) without those EWGs.

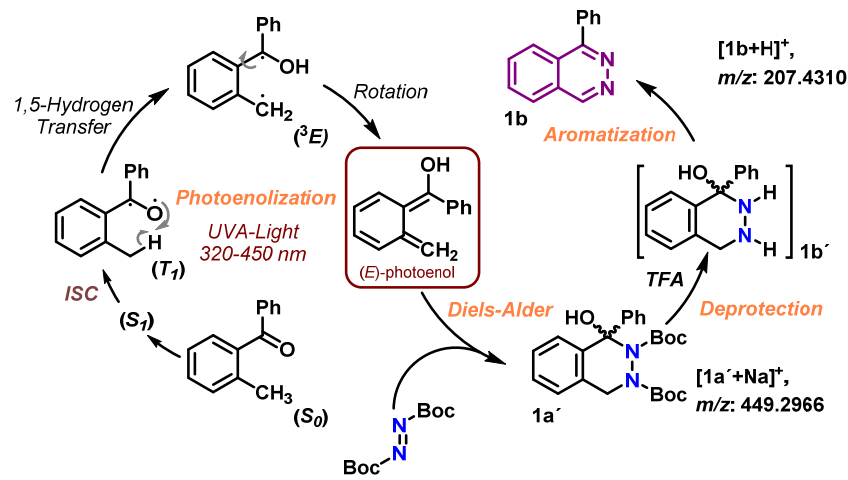

Figure 3. Proposed reaction mechanism of the light-driven metalfree one-pot reaction towards phthalazines.

According to the proposed mechanism for photoenolization, the singlet excited state $\left(\boldsymbol{S}_{1}\right)$, delivered by the direct irradiation of the substrate molecule in the ground state $\left(\boldsymbol{S}_{\boldsymbol{0}}\right)$, undergoes exclusive intersystem crossing (ISC) to the relatively long-lived triplet state $\left(\boldsymbol{T}_{\boldsymbol{I}}\right)$ (Figure 3). Adiabatic $\mathrm{H}$-atom transfer in the excited triplet ketone yields in triplet 1,4 biradical $\left({ }^{3} \boldsymbol{E}\right)$. Due to free rotation of the ketyl group in the relaxed geometry of ${ }^{3} \boldsymbol{E}$, initially both the $(Z)$ - and the $(E)$-photoenols are formed in about equal yield. However, the short-lived $(Z)$-dienol rapidly reverts to the starting ketone through efficient intramolecular 1,5-sigmatropic hydrogen shift. In contrast, $(E)$-photoenols are long-lived intermediates that can undergo reketonization to the starting material through a relatively slow solvent-mediated proton transfer. Once formed, the $(E)$-photoenol is trapped by di-tert-butyl azodicarboxylate forming tetrahydrophthalazin-1ol 1a'. Deprotection, accomplished with trifluoroacetic acid, initially delivers free tetrahydrophthalazin-1-ol 1b', which tends to release a molecule of water and hydrogen and aromatizes towards desired phthalazine $\mathbf{1 b}$.

\section{Conclusion}

In summary, we developed a first light-driven metal-free route towards 1-aryl-phthalazines, starting from o-methyl benzophenone derivatives and di-tert-butyl azodicarboxylate. Various substituents such as alkyl, alkoxy, halogen, nitrile and N-heterocycles are tolerated, while the starting materials are commercially available or easily accessible. This environmentally benign one-pot four-step reaction proceeds under mild conditions and in absence of catalysts or additives. 


\section{ACKNOWLEDGMENT}

We gratefully acknowledge financial support from the Deutsche Forschungsgemeinschaft (DFG, Grant TS 87/231 for S.B.T.). We also thank the Interdisciplinary Center for Molecular Materials (ICMM) for research support.

\section{REFERENCES}

(1) Asif, M. Some Recent Approaches of Biologically Active Substituted Pyridazine and Phthalazine Drugs. Curr. Med. Chem. 2012, 19 (18), 29842991.

(2) Crestey, F.; Knochel, P. Regioselective Functionalization of Chlorophthalazine Derivatives. Synthesis-Stuttgart 2010, 2010 (7), 10971106.

(3) Sangshetti, J.; Pathan, S. K.; Patil, R.; Ansari, S. A.; Chhajed, S.; Arote, R.; Shinde, D. B. Synthesis and Biological Activity of Structurally Diverse Phthalazine derivatives: A Systematic Review. Bioorg. Med. Chem. 2019, 27 (18), 3979-3997.

(4) Mathew, T.; Papp, A. Á.; Paknia, F.; Fustero, S.; Surya Prakash, G. K. Benzodiazines: recent synthetic advances. Chem. Soc. Rev. 2017, 46 (10), 3060-3094.

(5) Taek Han, Y.; Jung, J.-W.; Kim, N.-J. Recent Advances in the Synthesis of Biologically Active Cinnoline, Phthalazine and Quinoxaline Derivatives. Curr. Org. Chem. 2017, 21 (14), 1265-1291.

(6) El-Azm, F. S. A.; Mahmoud, M. R.; Hekal, M. H. Recent Developments in Chemistry of Phthalazines. Organic Chem. Curr. Res. 2015, 4 (1), 1000132.

(7) Rubin, L. J.; Peter, R. H. Oral hydralazine therapy for primary pulmonary hypertension. N. Engl. J. Med. 1980, 302 (2), 69-73.

(8) Price, B.; Pyne, N. J.; Houslay, M. D. Proteolysis of cyclic AMP phosphodiesterase-II attenuates its ability to be inhibited by compounds which exert positive inotropic actions in cardiac tissue. Biochem. Pharmacol. 1987, 36 (23), 4047-4054

(9) Hess-Stumpp, H.; Haberey, M.; Thierauch, K.-H. PTK 787/ZK 222584, a Tyrosine Kinase Inhibitor of all Known VEGF Receptors, Represses Tumor Growth with High Efficacy. Chembiochem 2005, 6 (3), 550-557.

(10) Jost, L.; Gschwind, H.-P.; Jalava, T.; Wang, Y.; Guenther, C.; Souppart, C.; Rottmann, A.; Denner, K.; Waldmeier, F.; Gross, G. Metabolism and disposition of vatalanib (PTK787/ZK 222584) in cancer patients. Drug Metab. Dispos. 2006, 34 (11), 1817-1828.

(11) Bromberg, K. D.; Mitchell, T. R.; Upadhyay, A. K.; Jakob, C. G.; Jhala, M. A.; Comess, K. M.; Lasko, L. M.; Li, C.; Tuzon, C. T.; Dai, Y.; et al. The SUV4-20 inhibitor A-196 verifies a role for epigenetics in genomic integrity. Nat. Chem. Biol. 2017, 13 (3), 317-324.

(12) Cui, H. L.; Feng, X.; Peng, J.; Lei, J.; Jiang, K.; Chen, Y. C. Chemoselective asymmetric N-allylic alkylation of indoles with MoritaBaylis-Hillman carbonates. Angew. Chem. Int. Ed. Engl. 2009, 48 (31), 5737-5740.

(13) Kapferer, T.; Brückner, R. Asymmetric Dihydroxylation of $\beta, \gamma-$ Unsaturated Carboxylic Esterswith Trisubstituted $\mathrm{C}=\mathrm{C}$ Bonds Enantioselective Syntheses of Trisubstituted $\gamma$-Butyrolactones. Eur. J. Org. Chem. 2006, 2006 (9), 2119-2133.

(14) Rashidi, M.; Nabavizadeh, S. M.; Zare, A.; Jamali, S.; Puddephatt, R. J. Associative and Dissociative Mechanisms in the Formation of Phthalazine Bridged Organodiplatinum(II) Complexes. Inorg. Chem. 2010, 49 (18), 8435-8443.

(15) Kuzelka, J.; Farrell, J. R.; Lippard, S. J. Modeling the Syn Disposition of Nitrogen Donors at the Active Sites of Carboxylate-Bridged Diiron Enzymes. Enforcing Dinuclearity and Kinetic Stability with a 1,2Diethynylbenzene-Based Ligand. Inorg. Chem. 2003, 42 (26), 8652-8662. (16) Xu, Y.; Fischer, A.; Duan, L.; Tong, L.; Gabrielsson, E.; Åkermark, B.; Sun, L. Chemical and Light-Driven Oxidation of Water Catalyzed by an Efficient Dinuclear Ruthenium Complex. Angew. Chem. Int. Ed. 2010, 49 (47), 8934-8937.

(17) Chan, K. P.; Hay, A. S. Thermal Rearrangement of a Phthalazine to a Quinazoline. J. Org. Chem. 1995, 60 (10), 3131-3134.

(18) Harikrishna, K.; Mukkamala, R.; Hinkelmann, B.; Sasse, F.; Aidhen, I. S. Iodine-Promoted Oxidative Conversion of o-Vinyl Diaryl Ketones into o-Acetyl Diaryl Ketones, Synthesis of 1-Methyl-4-arylphthalazines as Analogues of Podophyllotoxin. Eur. J. Org. Chem. 2014, 2014 (5), 10661075 .
(19) Lukacs, G.; Simig, G. Synthesis of new 1, 2-dihydrophthalazines. $J$. Heterocycl. Chem. 2002, 39 (5), 989-996.

(20) Robev, S. K. Phthalazine derivatives from aromatic aldazines Tetrahedron Lett. 1981, 22 (4), 345-348.

(21) Al-Mousawi, S. M.; Moustafa, M. S.; Elnagdi, M. H. A novel synthesis of 2-arylhydrazono-6-amino-4-arylbenzene-1,3-dicarbonitriles and their conversion into phthalazines. Tetrahedron Lett. 2009, 50 (46), 6411-6413. (22) Viña, D.; del Olmo, E.; Lopez-Pérez, J. L.; San Feliciano, A. Pyrazolo[3,4,5-de]phthalazine. Syntheses of a practically unknown heterocyclic system. Tetrahedron 2009, 65 (8), 1574-1580.

(23) Ju, Y.; Varma, R. S. Microwave-assisted cyclocondensation of hydrazine derivatives with alkyl dihalides or ditosylates in aqueous media: syntheses of pyrazole, pyrazolidine and phthalazine derivatives. Tetrahedron Lett. 2005, 46 (36), 6011-6014.

(24) Hayashi, Y. Pot economy and one-pot synthesis. Chem. Sci. 2016, 7 (2), 866-880.

(25) Grau, D.; Grau, B. W.; Hampel, F.; Tsogoeva, S. B. Three-Component Domino Knoevenagel/Vinylogous Michael Reaction: Entry to Challenging o-Terphenyls. Chem. Eur. J. 2018, 24 (25), 6551-6556.

(26) Bock, C. M.; Parameshwarappa, G.; Bonisch, S.; Neiss, C.; Bauer, W.; Hampel, F.; Gorling, A.; Tsogoeva, S. B. Generation of Complex Azabicycles and Carbobicycles from Two Simple Compounds in a Single Operation through a Metal-Free Six-Step Domino Reaction. Chemistry 2016, 22 (15), 5189-5197.

(27) Held, F. E.; Guryev, A. A.; Fröhlich, T.; Hampel, F.; Kahnt, A.; Hutterer, C.; Steingruber, M.; Bahsi, H.; von Bojničić-Kninski, C.; Mattes, D. S.; et al. Facile access to potent antiviral quinazoline heterocycles with fluorescence properties via merging metal-free domino reactions. Nat. Сommun. 2017, 8, 15071 .

(28) Kessler, S. N.; Wegner, H. A. One-Pot Synthesis of Phthalazines and Pyridazino-aromatics: A Novel Strategy for Substituted Naphthalenes. Org Lett. 2012, 14 (13), 3268-3271.

(29) Lang, X.; Chen, X.; Zhao, J. Heterogeneous visible light photocatalysis for selective organic transformations. Chem. Soc. Rev. 2014, 43 (1), 473486.

(30) Ravelli, D.; Fagnoni, M. Dyes as Visible Light Photoredox Organocatalysts. Chem CatChem 2012, 4 (2), 169-171.

(31) Hari, D. P.; Konig, B. Eosin Y catalyzed visible light oxidative C-C and C-P bond formation. Org. Lett. 2011, 13 (15), 3852-3855.

(32) Murphy, J. J.; Bastida, D.; Paria, S.; Fagnoni, M.; Melchiorre, P. Asymmetric catalytic formation of quaternary carbons by iminium ion trapping of radicals. Nature 2016, 532 (7598), 218-222.

(33) Bergonzini, G.; Schindler, C. S.; Wallentin, C. J.; Jacobsen, E. N.; Stephenson, C. R. Photoredox Activation and Anion Binding Catalysis in the Dual Catalytic Enantioselective Synthesis of beta-Amino Esters. Chem. Sci. 2014, 5 (1), 112-116.

(34) Filipovic, A.; Z, D. Z.; Vasiljevic-Radovic, D.; BondZic, B. P. Visible light promoted photoredox $\mathrm{C}(\mathrm{sp}(3))-\mathrm{H}$ bond functionalization of tetrahydroisoquinolines in flow. Org. Biomol. Chem. 2021, 19 (12), 26682675.

(35) Brachet, E.; Marzo, L.; Selkti, M.; Konig, B.; Belmont, P. Visible light amination/Smiles cascade: access to phthalazine derivatives. Chem. Sci. 2016, 7 (8), 5002-5006.

(36) Sammes, P. G. Photoenolisation. Tetrahedron 1976, 32 (4), 405-422. (37) Cuadros, S.; Melchiorre, P. Organocatalytic Strategies to Stereoselectively Trap Photochemically Generated Hydroxy-oquinodimethanes. Eur. J. Org. Chem. 2018, 2018 (23), 2884-2891.

(38) Cava, M. P.; Napier, D. R. Condensed Cyclobutane Aromatic Systems. II. Dihalo Derivatives of Benzocyclobutene and Benzocyclobutadiene Dimer1,2. J. Am. Chem. Soc. 1957, 79 (7), 1701-1705.

(39) Yang, N.; Rivas, C. A new photochemical primary process, the photochemical enolization of o-substituted benzophenones. J. Am. Chem. Soc. 1961, 83 (9), 2213-2213.

(40) Das, A.; Lao, E. A.; Gudmundsdottir, A. D. Photoenolization of oMethylvalerophenone Ester Derivative. Photochem. Photobiol. 2016, 92 (3), 388-398.

(41) Nakayama, T.; Hamanoue, K.; Hidaka, T.; Okamoto, M.; Teranishi, H. Photoenolization of 2-methylbenzophenone studied by picosecond and nanosecond laser spectroscopy. J. Photochem. 1984, 24 (1), 71-78.

(42) Nakayama, T.; Torii, Y.; Nagahara, T.; Hamanoue, K. Further study on intramolecular hydrogen-atom transfer originating from the lowest excited triplet state of 2-methylbenzophenone. J. Photochem. Photobiol. A 1998, $119(1), 1-7$. 
(43) Yamamoto, S.; Ebata, T.; Ito, M. Discrimination and selective reaction of rotational isomers of jet-cooled substituted benzaldehydes as studied by sensitized phosphorescence excitation spectroscopy. J. Phys. Chem. 1990, 94 (15), 5786-5791.

(44) Jin, P.; Wildman, T. A. Conformational behavior of 1-tetralone, 1benzosuberone, dibenzosuberone, and some structurally related aryl ketones from NMR spectroscopy. J. Phys. Chem. 1991, 95 (1), 20-25.

(45) Akiyama, K.; Ikegami, Y.; Tero-Kubota, S. Polarized ESR spectra of the triplet enols generated from o-methylacetophenone and related compounds. J. Am. Chem. Soc. 1987, 109 (8), 2538-2539.

(46) Suzuki, T.; Omori, T.; Ichimura, T. Excited-state reaction of shortlived 2-methylbenzophenone enols studied by stepwise two-color excitation time-resolved thermal lensing technique. J. Phys. Chem. A 2000, 104 (50), 11671-11676.

(47) Arnold, B. J.; Mellows, S. M.; Sammes, P. G.; Wallace, T. W. Photochemical reactions. Part II. Cycloaddition reactions with photoenols from 2-methylbenzaldehyde and related systems. J. Chem. Soc., Perkin Trans. 1 1974, (0), 401-409.

(48) Redmond, R. W.; Scaiano, J. C. Photoenol biradicals as singlet oxygen sensitizers. J. Phys. Chem. 1989, 93 (14), 5347-5349.

(49) Henderson, W. A.; Ullman, E. F. Photochemistry of 2-Benzyl- and 2Benzhydryl-3-benzoylchromones. J. Am. Chem. Soc. 1965, 87 (23), 54245433.

(50) Haag, R.; Wirz, J.; Wagner, P. J. The Photoenolization of 2Methylacetophenone and Related Compounds. Helv. Chim. Acta 1977, 60 (8), 2595-2607.

(51) Dell'Amico, L.; Fernández-Alvarez, V. M.; Maseras, F.; Melchiorre, P. Light-Driven Enantioselective Organocatalytic $\beta$-Benzylation of Enals. Angew. Chem. Int. Ed. 2017, 56 (12), 3304-3308.

(52) Charlton, J. L.; Koh, K. Asymmetric and Stereoselective Cycloaddition of the Acrylate and Fumarate of (R)-Methyl Mandelate to $\alpha$-Hydroxy-oquinodimethane. Synlett 1990, 1990 (06), 333-334.

(53) Dell'Amico, L.; Vega-Peñaloza, A.; Cuadros, S.; Melchiorre, P. Enantioselective Organocatalytic Diels-Alder Trapping of Photochemically Generated Hydroxy-o-Quinodimethanes. Angew. Chem. Int. Ed. 2016, 55 (10), 3313-3317.

(54) Cuadros, S.; Dell'Amico, L.; Melchiorre, P. Forging FluorineContaining Quaternary Stereocenters by a Light-Driven Organocatalytic Aldol Desymmetrization Process. Angew. Chem. Int. Ed. Engl. 2017, 56 (39), 11875-11879.

(55) Hepburn, H. B.; Magagnano, G.; Melchiorre, P. Light-Triggered Enantioselective Organocatalytic Mannich-Type Reaction. Synthesis 2017, 49 (01), 76-86.

(56) Paul, D. B. Synthetic approaches to phthalazines: C-N bond cleavage in 2'-benzylbenzohydrazides during reaction with polyphosphoric acid. Aust. J. Chem. 1984, 37 (4), 893-901.

(57) Aand, D.; Karekar, S.; Mahajan, B.; Pawar, A. B.; Singh, A. K. Controlled photo-flow oxidative reaction (UV-FOR) platform for ultra-fast phthalide and API synthesis. Green Chem. 2018, 20 (20), 4584-4590. 